Tadeusz Szczutko*

\title{
Technology of Precision Callibration of Electro-Optical Rangefinders Using Laboratory Methods and Field Test Baseline**
}

\section{Introduction}

Laboratory tests on rangefinders were performed in the Geodetic Metrology Laboratory of the Faculty of Mining Surveying and Environmental Engineering, AGH University of Science and Technology in Krakow. These measurements included marking the cyclic errors within the range of $30 \mathrm{~m}$, based on HP 5529A laser interferometer as a standard length. The range of $30 \mathrm{~m}$ is typical for industrial measurements, where precise total stations such as Sokkia NET05, Leica TDA5005 and the newest model Leica of TDA6100 are applied. Field tests were performed on the test baseline "Wisła" belonging to the Faculty of Mining Surveying and Environmental Engineering AGH UST in Krakow.

These procedures included laboratory and field use as the material constituting the basis for the complaint and accepting the claim by the manufacturer in case of the malfunction of the rangefinder in Trimble S8 Precise Total Station recommended by the manufacturer for the monitoring of structures and surface in the areas affected by mining. The accuracy of measuring the length of the rangefinder expressed by the standard error is $m_{D}= \pm(1 \mathrm{~mm}+1 \mathrm{ppm})$.

\section{Research on the Rangefinder of Trimble S8 Total Station}

\subsection{Introductory Remarks}

After noticing the differences in the distance measurements made with Trimble S8 Total Station No. 98010158, between the modes of Autolock and Standard, extensive studies of the instrument was initiated. All the actions of checking and rectification were carried out using internal programs of the instrument, as well as Autolock system. The study was carried out for the distance measurement in two operation modes of the instrument: Autolock and Standard. No studies on angle measurement systems were done.

\footnotetext{
* AGH University of Science and Technology, Faculty of Mining Surveying and Environmental
}

** Developed within the framework of the statutory research No. 11.11.150.006 


\subsection{Checking the Addition Constant}

Before delivering the rangefinder to the Geodetic Laboratory of Metrology, the user of the equipment made measurements to determine the addition constant of the set in the 5-point non-metric field baseline by measuring sections in all the combinations. The baseline of the length about $270 \mathrm{~m}$ consisted of tripods with precise heads by Leica situated colinearly. On this baseline 10 distances were measured, the measurements were carried out from each check point to the front. Addition constant was calculated by the least squares method, according to Schwendener (1972) [3]. This procedure, in a slightly modified form in terms of the calculations, is applied in the PN-ISO 17123-4:2005 standard concerning the testing of rangefinders [2].

The equations of the measured distances take the form:

where:

$$
D_{i j}+v_{i j}+c=X_{j}-X_{i},
$$

$D_{i j}$ - the length measured between points $i$ and $j$,

$v_{i j}$ - correction to the length,

$c$ - addition constant of the rangefinder-reflector set,

$X_{i^{\prime}} X_{i}$ - coordinates of the points calculated from the starting point alongside the baseline.

After transformation we obtain the correction equation:

$$
v_{i j}=-c+X_{j}-X_{i}-D_{i j} .
$$

As a result of solving the system, the addition constant for the set rangefinder-reflector is obtained, as well as the equalized values of the measured distances with the analysis of accuracy. Calculated values of the addition constant are in Table 1 (round precise reflector Leica GPH1P was used). Measurements were performed at temperature $t=2^{\circ} \mathrm{C}$ and pressure of $959.4 \mathrm{hPa}$ (read in S8) on 24 January 2009 .

Table 1. Calculation of the addition constant

\begin{tabular}{||l|c|c|c|c||}
\hline \multicolumn{1}{|c|}{ EDM Instrument } & Mode & $\begin{array}{c}\text { Internal accuracy } \\
\text { indicator } \\
m_{o}[\mathrm{~mm}]\end{array}$ & $\begin{array}{c}\text { Addition } \\
\text { constant } c \\
{[\mathrm{~mm}]}\end{array}$ & $\begin{array}{c}\text { MSE } \\
m_{c}[\mathrm{~mm}]\end{array}$ \\
\hline $\begin{array}{l}\text { Trimble S8 } \\
\text { No. 98010158 }\end{array}$ & Autolock - ON & 0.25 & -35.48 & 0.18 \\
\hline $\begin{array}{l}\text { Trimble S8 } \\
\text { No. 98010158 }\end{array}$ & Autolock - OFF & 0.15 & -34.58 & 0.10 \\
\hline $\begin{array}{l}\text { Leica TCA } 1800 \\
\text { No. 417515 }\end{array}$ & ATR - ON & 0.11 & 0.27 & 0.07 \\
\hline $\begin{array}{l}\text { Leica TCA } 1800 \\
\text { No. 417515 }\end{array}$ & ATR - OFF & 0.13 & 0.27 & 0.09 \\
\hline
\end{tabular}

The difference between the designated values of addition constant for rangefinder Trimble S8 in both modes is $0.9 \mathrm{~mm}$, which, taking into account the 
catalog-indicated accuracy of the instrument $m_{D}= \pm(1 \mathrm{~mm}+1 \mathrm{ppm})$ is a significant value. Based on the measurement results, it was also found that in addition to the constant difference of $0.9 \mathrm{~mm}$, in the lengths measured in the Autolock mode and without this mode, a difference occurs, equaling - depending on the distance about $2 \mathrm{~mm} / \mathrm{km}$. These differences should be removed in the factory service. In the examined on this occasion rangefinder Leica TCA 1800 total station the differences between the standard measurement and ATR are virtually non-existent.

\subsection{The Study of the Rangefinder Measurements within Short Distances Using a Laser Interferometer as a Pattern}

As a length pattern a laser interferometer HP 5529A was used (Fig. 1). The measurement was performed concurrently - at the same time the distances were measured with the rangefinder and the movement of the interferometer truck with the measurement reflector was recorded. The applied measurement method used does not allow checking the addition constant (it was done with the method described above). The distance was measured with rangefinder in Autolock and Standard modes. The length of the measurement baselineis $32 \mathrm{~m}$. The accuracy of the length measurement with the interferometer, after taking into account the errors of the track, is $0.01 \mathrm{~mm}$, which is ten times higher than the accuracy of reading the distance in precise rangefinder, which is $0.1 \mathrm{~mm}$.

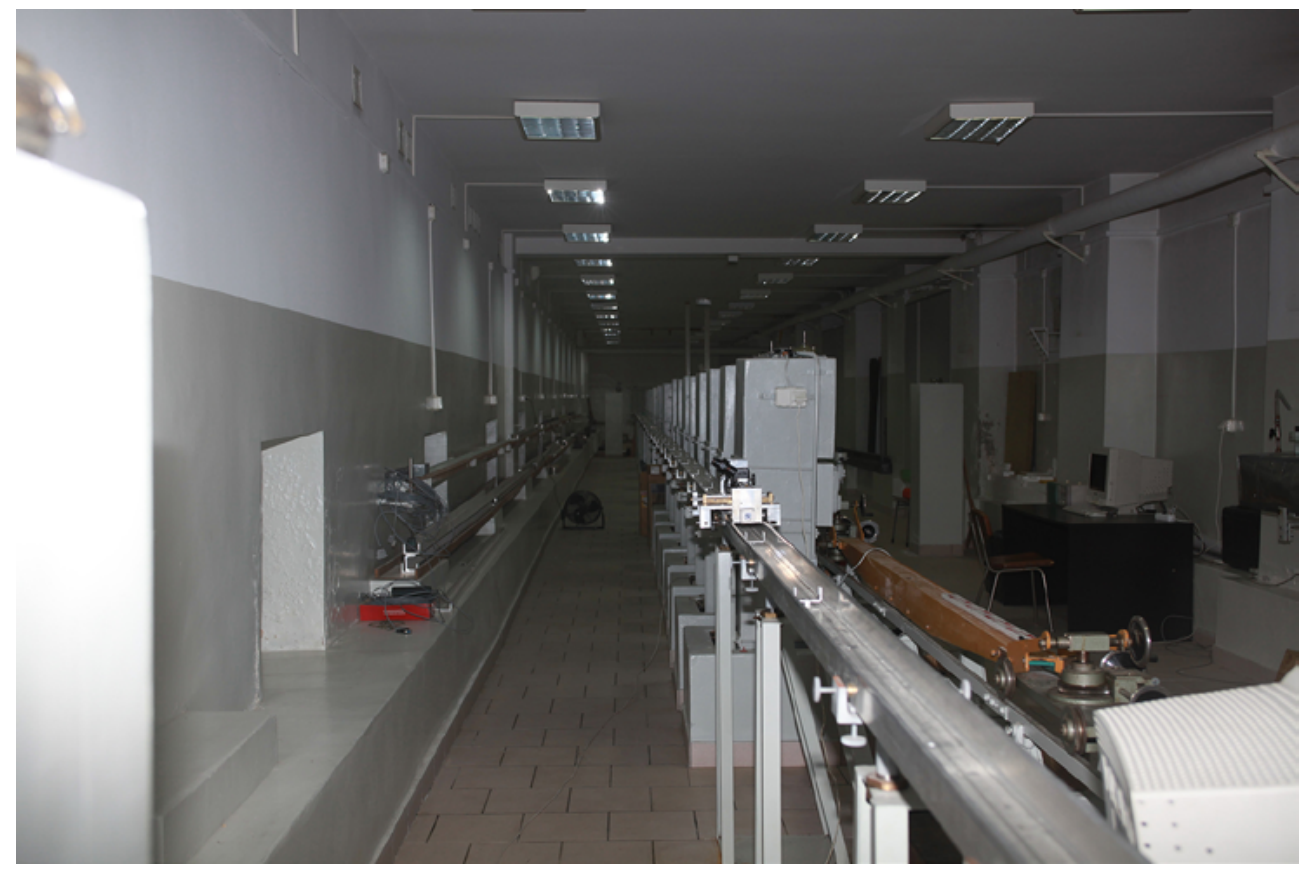

Fig. 1. Optical baseline in Geodetic Metrological Laboratory 
In every mode four length readings were made, for further calculations the mean value was taken. Mean values in both modes were compared to the readings of the interferometer. The measurement was related to the first mean distance measured in Autolock mode; the interferometer was zeroed at this point and further values of distance counted by the HP 5529A system were added. Based on the results of measurement graphs were made (Figs 2, 3).

\section{S8 nr 98010158 - 27.01.2009 - laser intefrerometer as a pattern length}

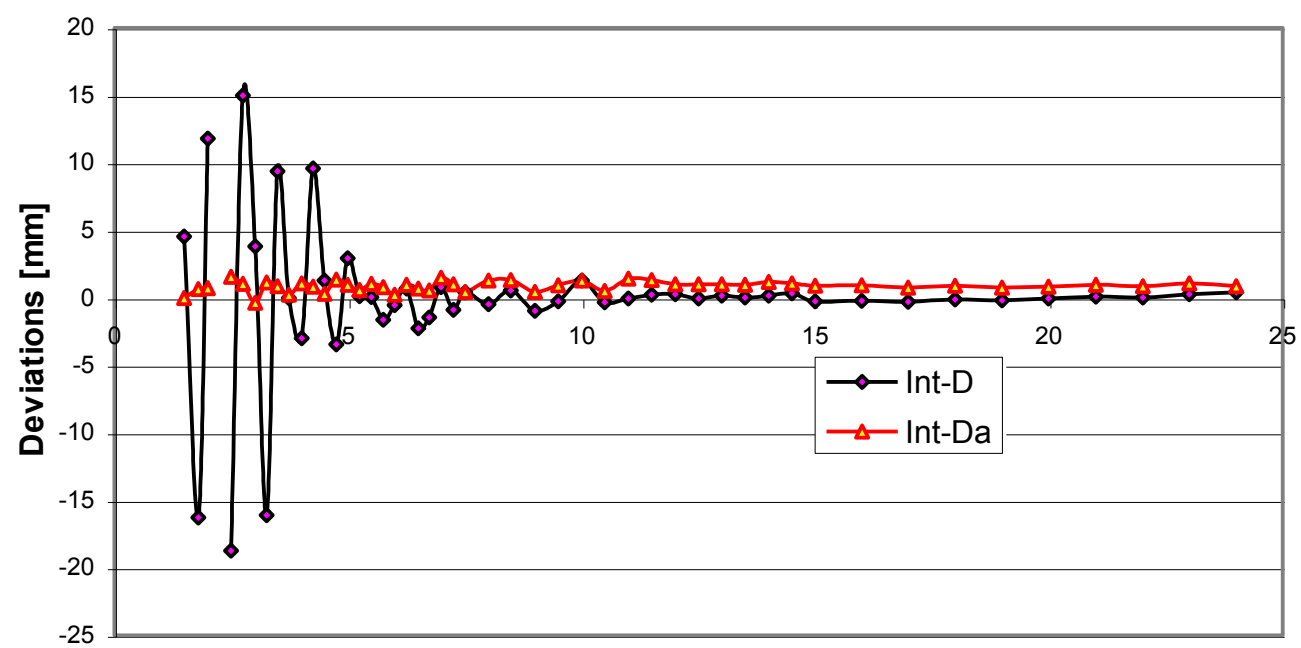

Measured length [m]

Fig. 2. The graph comparing total station S8 No. 91010158 with the interferometer: differences in relation to interferometer - Autolock (Int-Da) mode; mode without Autolock (Int-D)

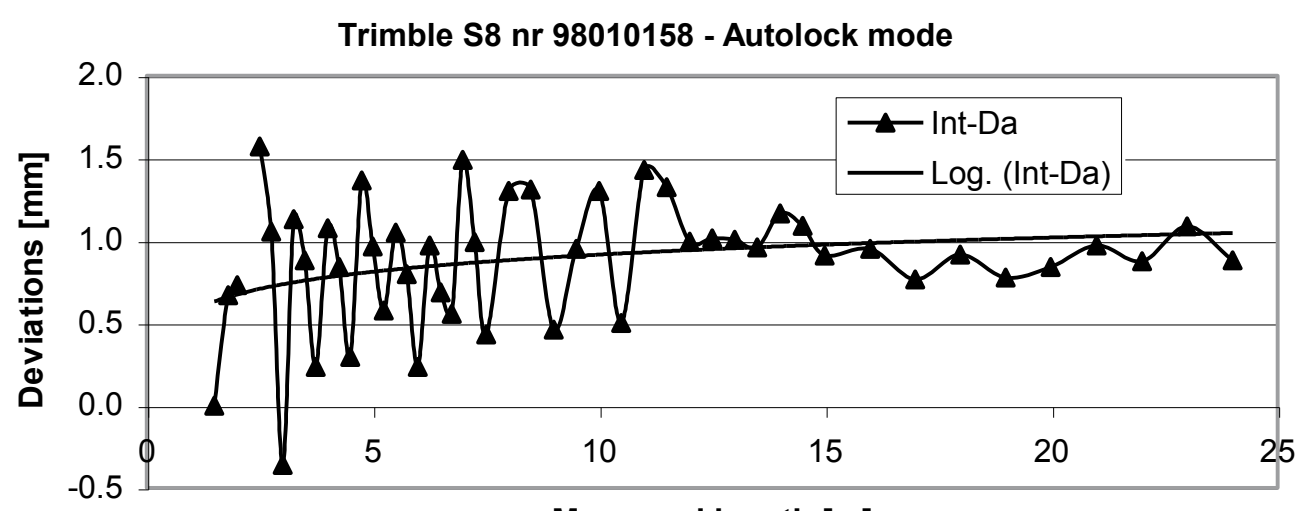

Measured length [m]

Fig. 3. The graph of the differences in relation to the interferometer - Autolock mode 
The measurements of the rangefinder are stable in the whole range of lengths measured in Autolock mode. There is a small curvature of the characteristics in the range of $15 \mathrm{~m}$, typical of most rangefinders [4]. After disabling this option in the range of less than $5 \mathrm{~m}$ one can expect errors of $\pm 15 \mathrm{~mm}$. It is too high value, because in the implementation work this distance range is applied. The calculated for the range of a stable operation of the rangefinder (distance of 12-24 m) difference between the distances measured alternately in Autolock and Standard mode is $0.91 \mathrm{~mm} \pm 0.18 \mathrm{~mm}$. This value is identical with the one obtained on the user's field baseline.

\subsection{Control of Trimble S8 Rangefinder after Repair Service}

In order to remove the systematic difference between the measurements indicated by rangefinder in Autolock mode and without this option and to improve EDM in the range of short distances, the instrument was sent for the regulation to the factory for calibration and the results of the research were enclosed. Figure 4 shows the result of the control of rangefinder S8 No. 98010158 after repair service. There is a complete compatibility of the indications of rangefinder in Autolock and Standard mode; maximum divergence of the readings are $\pm 1.4 \mathrm{~mm}$, compared to $\pm 15 \mathrm{~mm}$ before the repair.

\section{Trimble S8 nr 98010158 after repair service - measurement of 23.02.2009}

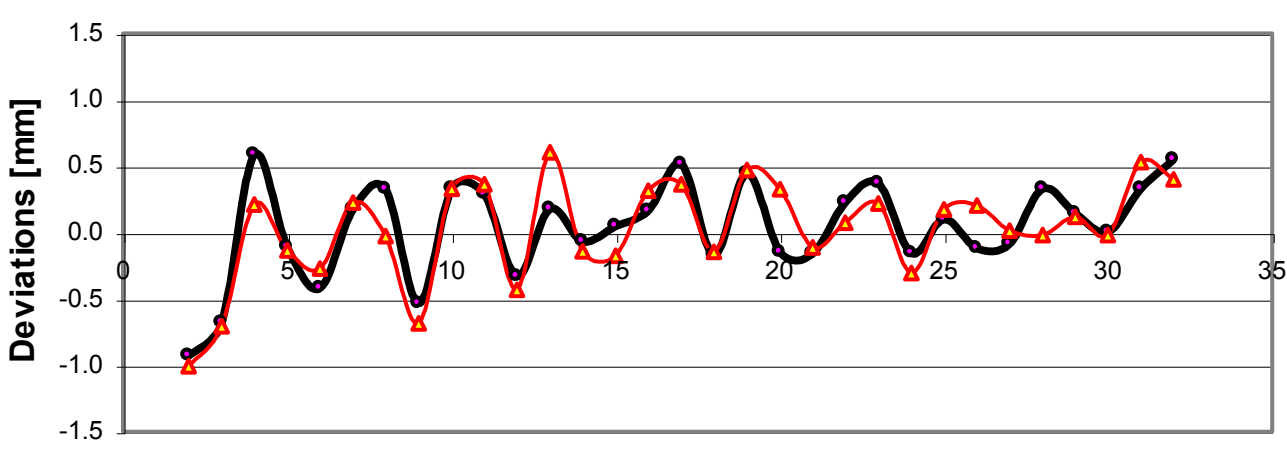

Measured length $[\mathrm{m}]$

Fig. 4. The graph comparing Total Station S8 No. 91010158 with the interferometer after the repair service (measurement series marked as in Figure 2)

\subsection{Examples of Test Measurements of Other Rangefinders}

Instruments designed to operate in the short distances are industrial total stations, Leica TDA 5005 [1] and Sokkia NET05. Rangefinder TDA5005 provides accuracy $m_{D}= \pm(1 \mathrm{~mm}+2 \mathrm{ppm})$ range up to $120 \mathrm{~m}$ and an accuracy of $\pm 0.5 \mathrm{~mm}$, while on the prism reflector $\pm 0.2 \mathrm{~mm}$. NET05 reflective foil (if its plane is perpendicular to the line of sight $)$ is measured with the accuracy of $m_{D}= \pm(0.5 \mathrm{~mm}+1 \mathrm{ppm})$ and with prismatic reflector $m_{D}= \pm(0.8 \mathrm{~mm}+1 \mathrm{ppm})$. 
Leica TDA 5005 - measurement 11.04.2011

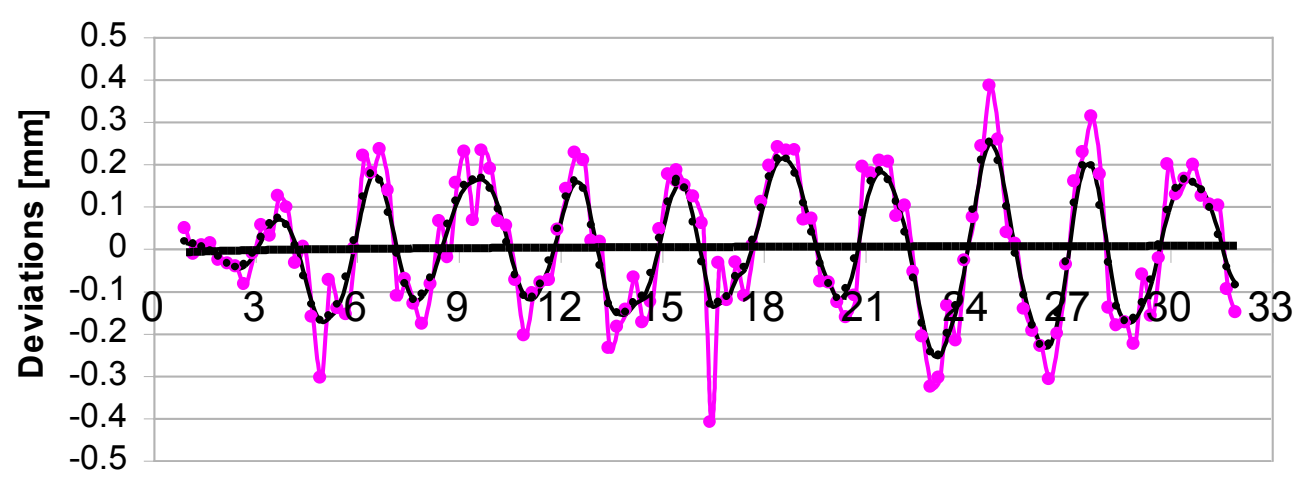

\section{Mesured length [m]}

Fig. 5. Industrial Total Station Leica TDA 5005 - chart of cyclic errors

Figure 5 shows the test result of examining Leica TDA 5005 based on interferometry using the Leica GPR1 reflector. The graph clearly shows the cyclic error with amplitude of about $0.2 \mathrm{~mm}$ and period of $3 \mathrm{~m}$ (half a length of the calibration wave).

Causes of cyclic error can be the following:

- the aging of electronic components, resulting in deregulation of EDM equipment,

- the producer allows the occurrence of rudimentary values of cyclic error, provided that they are within the accuracy declared by the producer.

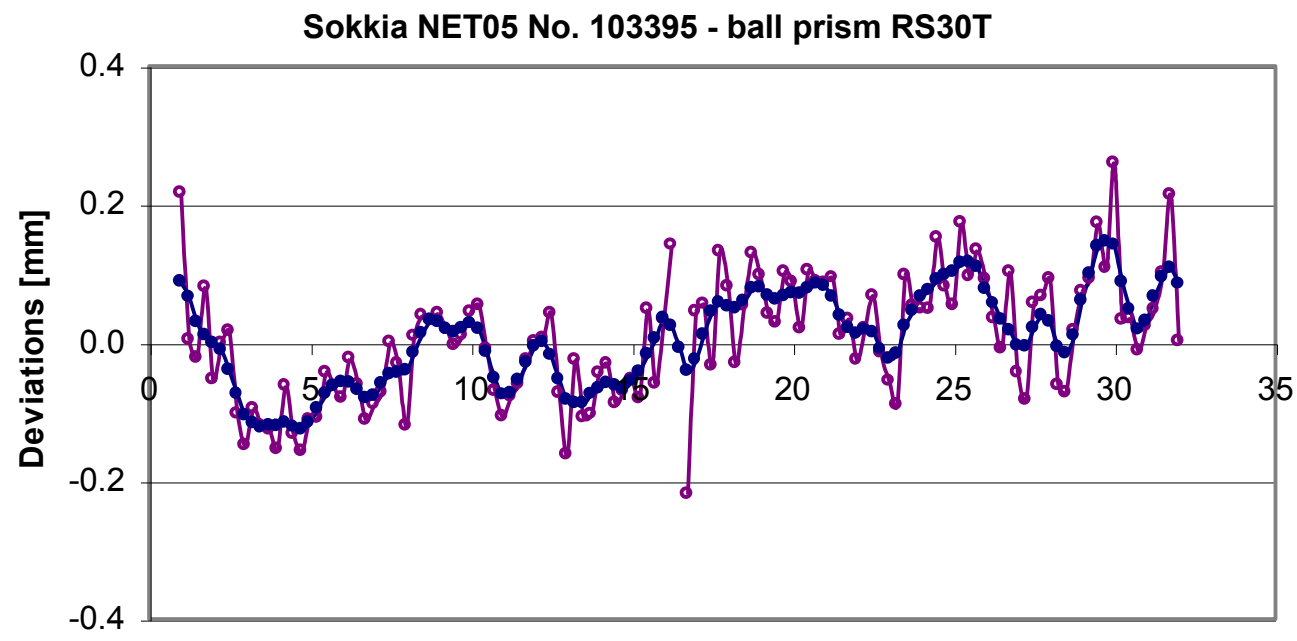

Measured length [m]

Fig. 6. Comparison between the rangefinder of the Total Station Sokkia NET05 and the interferometer 
The lack of the possibility of obtaining a similar instrument for testing does not allow unambiguous solution of this problem. Before making measurements of the highest precision, the instrument should be regulated in the factory service and re-checked on the interferometer.

In the rangefinder of Total Station Sokkia NET05 the result of the measurement depends on the type of reflector. The difference between the reflector inside the dome housing RS30T designed for industrial measurement and reflector Leica GPH1P for a length of $30 \mathrm{~m}$ gives the differences of $0.2 \mathrm{~mm}$. It is the size of the corresponding measurement accuracy and precise measuring instrument should be considered. In industrial applications, the manufacturer usually proposes the application of reflective film. In Figure 6 a broken line marks the results of the comparison between the interferometer with double smoothing using the moving average of the ratio $k=3$. TS30T ball reflector was applied. The graphs show that both tested rangefinders allow obtaining the measurement accuracy provided by the manufacturer [6].

\section{Field Tests}

\subsection{Introduction}

The test baseline "Wisła" belongs to the Faculty of Mining Surveying and Environmental Engineering AGH UST in Krakow. It is located on a straight-line section of the anti-flood embankment of the Vistula River, on its right bank, within the administrative borders of the city of Krakow (Fig. 7).

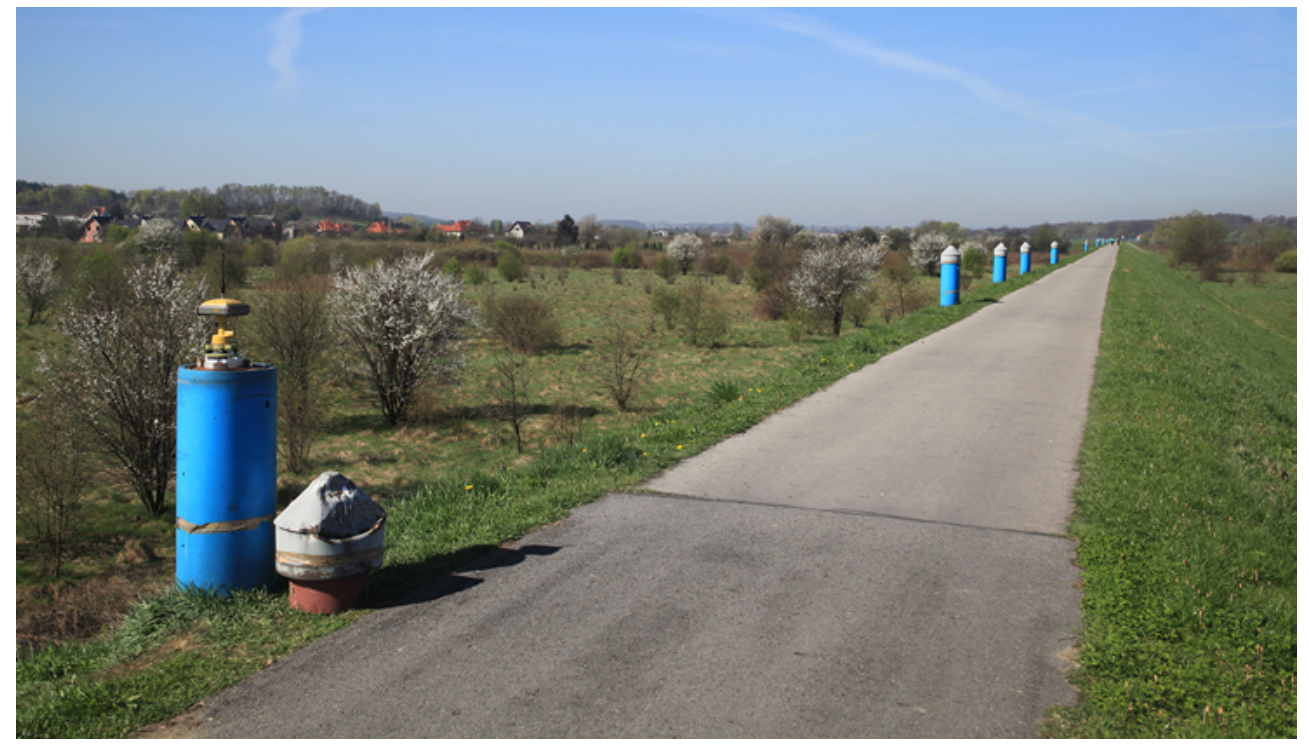

Fig. 7. Test Baseline "Wisła" - view from the starting point to the west 
It consists of 20 pillars with the measuring heads of Kern, allowing precise forced centering, distributed over the length of $1230 \mathrm{~m}$. The effective lengths of the baselinewere determined by Wild Di2002 rangefinders. Since April 2010, the lengths of the baselinehave been controlled every six months, also using other types of precise rangefinders and GPS [5]. The measurement with the rangefinders were made with the control of their reference frequency in the field, using a precise frequency meter HP 53131A.

Bad weather and limited availability did not allowed performing field tests of rangefinders TDA5005 and Sokkia NET05 - as far as rangefinders described above are concerned - measurements were made only by Trimble S8 Total Station. Designated after the repair in Standard mode addition constant on field test baseline "Wisła" $c=-34.57 \mathrm{~mm} \pm 0.30 \mathrm{~mm}$ (compared to $-34.58 \mathrm{~mm}$ designated on the user's non-metric baseline before the repair). The addition constant on the "Wisła" baseline was designed after adopting the standard lengths, defined earlier [5] using two rangefinders Di2002.

\subsection{Optimization of the Calculation of Atmospheric Correction to the Measured Lengths}

The accuracy of calculating atmospheric correction determines the accuracy of the measurement results of the rangefinder. Based on the experience from the measurements made on the "Wisła" baseline, a method to optimize the calculation of the correction was created. Theoretically the measurement of pressure and temperature should be made at the end of the measurement section, but field studies did not yield the expected results. In the case of analog instruments, such as thermometers and aneroids, it is important to read carefully the indications at exactly the same moment and in the same manner. A person busy with setting the reflector would have to wait quite a long time to obtain the results from the thermometer and barometer corresponding to the actual parameters of the environment. Therefore, to shorten the measurement time, it is necessary to apply another procedure that would provide a similar result referring to atmospheric conditions at the end of the measured section. The application of electronic equipment recording atmospheric parameters would allow recording the results exactly at the same time, but the drawback is considerable inertia and non-linearity of the sensors. Is it possible to increase the accuracy of the designation of the correction, measuring atmospheric parameters only at this checkpoint? In order to determine the reference length of the baseline as well as to check precise rangefinders, the distances are measured from three selected points: the initial point (0), middle point (11) and ending point (19) towards all the other points. Thus in a relatively long time the measurement o 19 distances from each point are made. We are dealing with time series, where in the function of time there are observations of air temperature, pressure and humidity. The temperature at the check point is measured by a psychrometer where the smallest distance of the scale is $0.2^{\circ} \mathrm{C}$. Theoretically, the temperature can be read with the accuracy of $0.1^{\circ} \mathrm{C}$. The temperature is read in the shade, the air circulation is provided by an electric 
motor fan. To measure the pressure with the accuracy of $0.1 \mathrm{mmHg}$ the Bertrand aneroid is used. Both instruments are checked by the temperature and pressure sensor being a component of the laser interferometer system HP 5529A - HP 10751C. Due to the failure of the electronic hygrometer the air humidity $\mathrm{h} \%$ was assumed with the accuracy of $10 \%$ from the online weather forecast by the Warsaw University.

During the measurement, it is noticed that even a slight change in the density of the clouds immediately causes the change of the temperature and pressure.

The following questions arise:

- Is the measurement of the error, associated with the inertia of the thermometer and aneroid, not greater than the actual changes in temperature and pressure?

- Do the refractive index and the related atmospheric correction of length change immediately or with certain delay?

The above questions change into hypotheses, which can be accepted or rejected, if we have a suitable set of observations. The first of these hypotheses can be verified based on the accumulated during measurements results of pressure, temperature and length readings after their adequate processing.

Based on the measured temperature parameters, the value of the atmospheric correction $\mathrm{ppm}_{\mathrm{atm}}$ is calculated. The moment of observation and the value $\mathrm{ppm}_{\mathrm{atm}}$ creates a time series: $\mathrm{ppm}_{\mathrm{atm}}=f\left(t, \mathrm{ppm}_{\mathrm{atm}} \mathrm{h} \%\right)$. The measurements of pressure, temperature and air humidity create time sequences that can be analyzed separately, but it is more convenient to for the calculations take their function i.e. atmospheric correction of the length. Assuming that the duration of a single measurement of distance on the baseline is the same, we get three time series of the values of atmospheric correction, separately for each position.

These series are loaded with:

- the errors of reading atmospheric parameters,

- local changes in these parameters,

- the influence of the inertia in the apparatus.

Assuming that the change of the state of the atmosphere, and hence atmospheric correction of the distance does not occur rapidly, but there is a certain inertia of the atmosphere, a model computing the length of the baseline was proposed. The ppm values obtained by the smoothing of the time series were used in the model. One of the methods of smoothing time series is the moving average, often used in forecasting economic performance. In this case, the moving average is not used in forecasts, but every newly calculated value concentrates around the current value. The moving average is a type of low-pass filter. As a result of its application a smoothed time series is obtained (discrete values on the trend line), and the local distortions of the series are removed. Based on our considerable experience in presenting the results of some surveying having the character of time series, double smoothing of the ppm value calculated with the moving average with the coefficient 3 was applied. 
The new value of $x_{i}$ at a given point is calculated as follows:

where:

$$
\begin{aligned}
& x_{i}^{1}=\frac{x_{i-1}+x_{i}+x_{i+1}}{3}, \\
& \mathrm{x}_{i}^{2}=\frac{\mathrm{x}_{i-1}^{1}+\mathrm{x}_{i}^{1}+\mathrm{x}_{i=1}^{1}}{3}
\end{aligned}
$$

$x_{i}$ - the calculated atmospheric correction,

$x_{i}^{1}$ - average value after the first smoothing,

$\mathrm{x}_{i}^{2}$ - average value after the second smoothing.

The first and last element of the new series is the arithmetic mean of the first two and the last two elements of the processed series. Figure 8 shows a graph of calculated atmospheric corrections and - after smoothing - double moving average for the measurement series on the "Wisła" baseline.

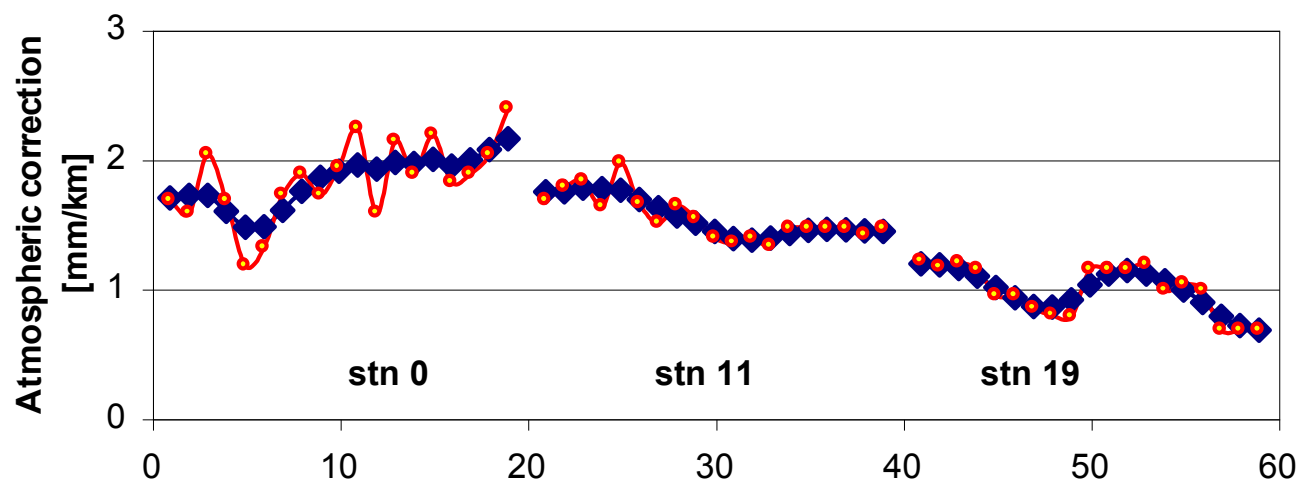

Fig. 8. Graph of atmospheric correction - the measurement of 04/07/2010

The application of the described method for determining the atmospheric correction reduces the mean compensation error of the baseline length with the Schwendener method [3]. Table 2 shows the comparison of the two types of precise rangefinders Wild/Leica.

This procedure can be used for the measurements of precise engineering objects. The continuation of the research is planned to determine the dynamics of changes of atmospheric correction caused by the changes in temperature, pressure and humidity.

Table 2 shows that the internal accuracy of EDM for the final result may be of secondary importance, but the stability of the atmosphere is important during the measurement. Partial results of measurements made on the "Wisła" baseline were discussed in literature [5]. 
Table 2. Increase of the accuracy after smoothing the calculated atmospheric correction with the moving average method

\begin{tabular}{|c|c|c|c|}
\hline \multirow[b]{2}{*}{ EDM instrument } & \multicolumn{2}{|c|}{ Coefficient $m_{0}$ after adjustment (mm) } & \multirow{2}{*}{$\begin{array}{c}\text { Increase } \\
\text { in accuracy } \\
(a-b) / a \cdot 100 \%\end{array}$} \\
\hline & $\begin{array}{l}\text { Calculated } \\
\mathrm{ppm}_{\text {atm }} \\
(a)\end{array}$ & $\begin{array}{l}\text { Smoothed } \\
\mathrm{ppm}_{\text {atm }} \\
(b)\end{array}$ & \\
\hline $\begin{array}{l}\text { Leica TCA2003 } \\
\text { No. } 438337\end{array}$ & 0.345 & 0.299 & 13 \\
\hline $\begin{array}{l}\text { Leica TCA2003 } \\
\text { No. } 664662\end{array}$ & 0.226 & 0.216 & 4 \\
\hline $\begin{array}{l}\text { Leica DI2002 } \\
\text { No. } 180650\end{array}$ & 0.222 & 0.191 & 23 \\
\hline $\begin{array}{l}\text { Wild Di2002 } \\
\text { No. } 180231\end{array}$ & 0.199 & 0.167 & 16 \\
\hline
\end{tabular}

\subsection{Calibration or Comparation}

Length measurement based on the combined designation allows the determination of the addition constant for the set rangefinder-reflector and the corrections of the rangefinder's scale.

Due to the fact that the tested range finders have similar accuracy as the reference lengths of the baseline, which are determined using precise rangefinders and GPS measurement - instead of comparison with the "master" lengths of the baseline - a two-step testing procedure was used:

1. the aligning of the observations carried out with the tested rangefinder in a one-dimensional local system of the database by Schwendener's method involving the elimination of the systematic factor in the form of the addition constant and the calculation of the aligned lengths of the baseline with the full evaluation of the accuracy; the procedure is defined as a self-calibration of the range finder;

2. comparison of aligned baseline length of calibrating lengths obtained from previous measurements and calculations based on a scale correction.

Figure 9 shows an example of the comparison of Leica TS11 rangefinder with the standard error $m_{D}= \pm(1 \mathrm{~mm}+1.5 \mathrm{ppm})$ after comparison of the measurement on the base, with the baseline lengths determined with two rangefinders Di2002. This rangefinder is used as a model at the service point for the surveying equipment. The points of the base, on which the differences are greater should be analyzed in terms of stability.

This is the method that gives more reliable results for the precise rangefinders. This enables us to evaluate the internal accuracy introduction of the rangefinder at the very beginning and then to assess the scale difference in the relation to the length 
of the test database. You can additionally detect the dislocation of the base poles and eliminate erroneous calculation points. Instead of the word "calibration", which means the designation of the parameters of the hardware based on the pattern, one should use the word "comparation", i.e. a comparison of the equipment with the test baseline of similar accuracy.

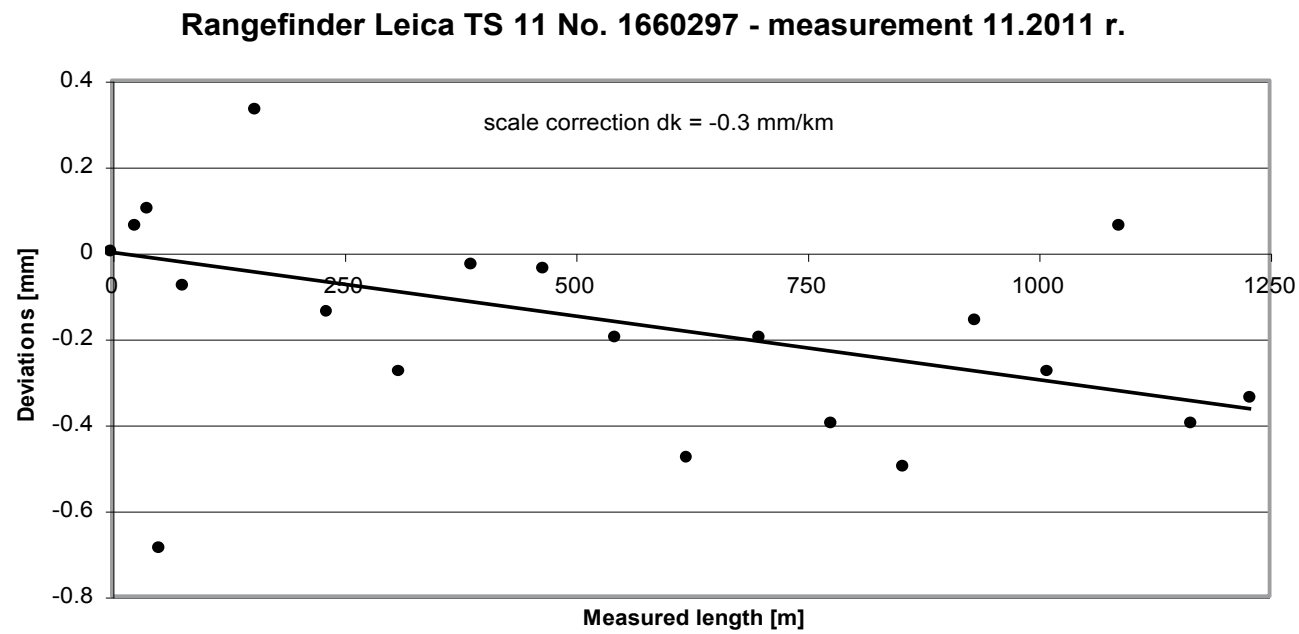

Fig. 9. Determination of the scale correction in the precise rangefinder on the "Wisła" baseline

\section{Conclusions}

Calibration, i.e. the designation of operational parameters of precise rangefinders is a set of technical procedures to little extent covering the issues of legal metrology.

Depending on the needs of the contractor, it is possible to perform only a part of the research essential for future applications of the equipment. Depending on whether the total station is intended for industrial measurements, deformation measurements, surveying of geodetic network or there is a need to describe the damage to the equipment, a separate test group should be offered.

For the user of the equipment it is essential that, apart from the designated technical parameters of the rangefinder, the conditions of the use of equipment are determined, taking into account external factors. As a pattern for testing precise rangefinders in the laboratory the laser interferometer should be applied. In the process of the calibration of precise rangefinders the field test baseline is complementary to laboratory baselines. 


\section{References}

[1] Gottvald R., Müller I., Obrist M.: Leica TDA5000 - Short Range Performance Tests using Corner Cube and Tooling Ball Reflectors. FHBB Basel Institute of Technology, Switzerland Department of Surveying \& Geoinformation Systems, 2011.

[2] PN-ISO17123-4:2005: Optyka i instrumenty optyczne. Terenowe procedury testowania instrumentów geodezyjnych i pomiarowych. Część 4: Dalmierze elektrooptyczne (instrumenty EDM).

[3] Schwendener H.R.: Electronic distancers for short ranges: accuracy and checking procedures. Survey Review, vol. 21, issue 164, 1972, pp. 273-281.

[4] Szczutko T.: Badania związane $z$ występowaniem błędów cyklicznych w precyzyjnych dalmierzach elektrooptycznych. Geomatics and Environmental Engineering, vol. 1, no. 1/1, 2007, pp. 203-211.

[5] Szczutko T., Frukacz M., Buśko M.: Application of precise distancers and GPS receivers for lenght determination and Krakow-located "Wista" calibration baseline stability control. Reports on Geodesy, z. 1/90, 2011, pp. 477-484.

[6] Websites: www.sokkia.com, www.leica-geosystems.com, www.icm.edu.pl. 